\title{
Peran Gaya Kepemimpinan terhadap Motivasi dan Kinerja Karyawan di PT. Infineon Technologies Batam
}

\author{
Yulinda Tarigan* dan Mangaraja Sahat Parulian Pandiangan* \\ * Batam Polytechnics \\ Applied Business Administration Study Program \\ Jalan Ahmad Yani, Batam Center, Batam 29461, Indonesia \\ E-mail : yulinda@polibatam.ac.id* \& rajapandiangan26@gmail.com*
}

\begin{abstract}
Abstrak
Penelitian ini bertujuan untuk mengetahui peran gaya kepemimpinan terhadap motivasi dan kinerja karyawan pada PT. Infineon Technologies Batam. Variabel penelitian ini adalah motivasi kerja (X1) dan kinerja karyawan (X2). Pendekatan penelitian menggunakan kuantitatif dan menggunakan uji asumsi klasik, regresi linier berganda, uji T dan uji F. Populasi sebanyak 112 dan sampel penelitian berjumlah 88 responden. Pengumpulan data untuk penelitian ini menggunakan kuesioner yang terdiri dari 11 item/pernyataan indikator. Hasil penelitian dengan tingkat signifikansi 0,05 menunjukkan bahwa gaya kepemimpinan berpengaruh positif dan signifikan terhadap motivasi kerja karyawan dimana $\mathrm{T}$ count 8,770> $\mathrm{T}$ table 1,98827 dan gaya kepemimpinan memiliki pengaruh positif dan signifikan terhadap kinerja karyawan dimana $\mathrm{T}$ count 0,426 > T table 1.98827. Selain itu gaya kepemimpinan memiliki pengaruh positifi dan signifikani terhadapi motivasi dan kinerja secara bersamaan.
\end{abstract}

Kata kunci: Gaya Kepemimpinan, Motivasi, Kinerja.

\begin{abstract}
The purpose of this research is to examine the effect of leadership style on employee motivation and performance at PT. Infineon Technologies Batam. The variables of this research are work motivation (X1) and employee performance (X2). The research approach uses quantitative and uses classical assumption test , multiple linear regression, $\mathrm{T}$ test and $\mathrm{F}$ test. The population and research sample are 88 respondents. Data collection for this study used a questionnaire consisting of 11 items/indicator statements. The results with a significancei level of 0.05 indicate that leadership style has a positive and significant effect on employee work motivation where $\mathrm{T}$ count 8,770 $>\mathrm{T}$ table 1,98827 and leadership style does have a positive and significant effect on employee performance where $\mathrm{T}$ count $0.426>\mathrm{T}$ table 1.98827. In addition, leadership style has a positive and significant influence on motivation and performance simultaneously.
\end{abstract}

Keywords: Leadership Style, Motivation, Employee Performance. 


\section{Pendahuluan}

Tujuan suatu perusahaan adalah untuk mencapai kerja sama antar pelaku perusahaan agar berjalan dengan lancar. Pemimpin tidak akan mampu menguasai situasi perusahaan tanpa kerjasama yang baik dengan bawahannya (Kesuma, 2019)

Seperti yang kita sadari bahwa setiap organisasi memiliki teknik untuk bersaing dalam menghadapi era globalisasi saat ini. Salah satu metodologi yang dapat digunakan adalah teknik aset manusia, mengingat SDM merupakan sudut pandang yang vital dalam pengelolaan suatu organisasi. SDM dalam organisasi terdiri dari pionir dan perwakilan. Setiap orang memiliki kapasitas dan pekerjaannya masing -masing .Gaya kepemimpinan juga berubah seiring dengan perkembangan zaman dan perkembangan teori -teori kepemimpinan baru. Selain mendekati karakteristik pemimpini, kemungkinan, kelompok, dan teori jalur-tujuan kepemimpinan . beberapa hipotesis berbeda telah muncul akhir-akhir ini termasuk terobosan, administrasi yang menarik, penggantian, psikologis sosial, dan spekulasi positif yang kredibel. Hipotesis inisiatif ini menarik para analis untuk mengeksplorasi lebih jauh, salah satunya adalah gaya otoritas yang inovatif.

Gaya inisiatif juga berubah seiring dengan waktu dan peningkatan hipotesis otoritas baru. Serta bergerak menuju atribut perintis, hasil potensial, pertemuan, dan spekulasi otoritas yang objektif. Beberapa spekulasi yang berbeda telah muncul akhir-akhir ini termasuk terobosan, inisiatif memikat, penggantian, intelektual sosial, dan hipotesis pasti nyata. Hipotesis otoritas ini menarik para analis untuk menyelidiki lebih lanjut, salah satunya adalah gaya inisiatif terobosan.

PT Infineon Technologies Batam adalah sebuah organisasi Jerman yang bergerak di bidang semikonduktor yang didirikan pada bulan April 1999. Hasil fundamental dari PT. Infineon Technologies Batam adalah sirkuit terpadu di bidang: Memori komputer (DRAM, memori beruntun), simpang susun (berkabel dan tidak berkabel), aplikasi mekanik dan mobil, dan kartu rusak. Salah satu item yang paling up to date adalah TriCore MCU. Saat ini, Infineon Technologies memiliki sekitar 36.000 spesialis di seluruh dunia. Sebelum mendunia, PT. Infineon Technologies bekerja melalui perusahaan pembantu Amerika yang terletak di San Jose, California, di wilayah Asia-Pasifik di Singapura, Korea Selatan dan di Tokyo, Jepang.

PT. Infineon Technologies Batam saat ini mengalami fase di mana banyak karyawan absen dari pekerjaan, terlambat bekerja dan akhirnya karyawan diberhentikan. Di masa depan ini akan berdampak negatif pada kelangsungan hidup perusahaan dan juga kenyamanan karyawan.
Padahal PT. Infineon Technologies Batam adalah salah satu perusahaan semikonduktor terbaik di setiap cabang Infinieon yang tersebar di seluruh dunia. Perlu ada sikap tegas dari seorang pemimpin untuk menanggapi kasus-kasus seperti ini.

Oleh karena itu, untuk meningkatkan dan menjaga kualitas dan nama baik perusahaan, saya menyadari bahwa peran sumber daya manusia untuk menjadikan karyawan unggul dan ulet serta profesional di bidangnya sangat penting untuk pencapaian tujuan perusahaan. Oleh karena itu, seorang pemimpin diharapkan dapat menerapkan gaya kepemimpinan sesuai dengan porsi di era modern saat ini untuk mempengaruhi dan memimpin karyawannya sehingga dapat meningkatkan motivasi dan kinerja karyawan perusahaan. Inilah alasan saya mengangkat judul "Analisis Pengaruh Gaya Kepemimpinan terhadap Motivasi dan Kinerja Karyawan di PT. Infineon Technologies Batam"

\section{Tinjauan Literatur}

- Penelitian dari Huo-Tsan Chang, Yu-Jia Chou, Min-Chih Miao, \& Jia-Wen Liou (2019) dengan judul "Efek gaya kepemimpinan terhadap kualitas layanan: pengayaan atau menipisnya perilaku inovasi dan standardisasi pekerjaan". Hasil dari penelitian ini adalah kepemimpinan transformasional secara positif memengaruhi perilaku inovasi, yang memiliki efek positif pada kualitas layanan karyawan.

- Penelitian dari Bronto Kesuma \& Harun Syamsuddin (2019) dengan judul "Pengaruh Gaya Kepemimpinan Demokratis juga Motivasi terhadap Kinerja Karyawan PT. Panin Bank Cabang Atmo Palembang". Hasil peneletian ini adalah terdapat pengaruh gaya kepemimpinan demokratis dan motivasi terhadap Kinerja karyawan PT.Panin Bank Cabang Atmo Palembang.

- Penelitian dari Bella Nelfa Audina, Demak Claudia Yosephine Simanjuntak, Desrahmat Buulolo, Diego Andreas Lumban Tobing, \& Putra Sanjaya (2019) dengan judul "Pengaruh Gaya Kepemimpinan dan Komunikasi Terhadap Kinerja Karyawan pada PT. Bintang Rezeki Maju Medan”. Hasil penelitian ini adalah gaya kepemimpinan berpengaruh positif dan signifikan terhadap kinerja karyawan pada PT Bintang Rezeki Maju Medan. 
- Penelitian dari Muhammad Asrar-ul-Haq, K.Peter Kuchinke (2016) dengan judul "Dampak gaya kepemimpinan terhadap sikap karyawan terhadap pemimpin dan kinerja mereka: Bukti Empiris dari Bank Pakistan". Hasil dari penelitian ini adalah Gaya kepemimpinan transformasional dianggap sebagai gaya kepemimpinan paling efektif di Pakistan dan menegaskan bahwa teori Kepemimpinan rentang penuh didukung dalam pengaturan Pakistan.

\section{Metode Penelitian}

\subsection{Populasi dan Sampel}

Populasi yang dipakai dalam penelitian ini merupakan karyawan yang bekerja di lima departemen terpilih yaitu Human Resources Department, Quality Management, Logistics, Information Technology dan Facilities Management yang sudah berkerja lebih kurang dua tahun berjumlah 112. Penentuan ukuran sampel yang diambil menggunakan rumus slovin dengan margin error sebesar 0,05\%.

Perhitungannya adalah:

$$
\begin{aligned}
& \mathrm{n}=\mathrm{N} /\left(1+\left(\mathrm{N} \times \mathrm{e}^{2}\right)\right) \\
& \text { sehingga: } \\
& \mathrm{n}=112 /(1+(112 \times 0,052)) \\
& \mathrm{n}=112 /(1+(112 \times 0,0025)) \\
& \mathrm{ni}=87,5 \text { dibulatkan menjadi } 88
\end{aligned}
$$

Cara mendistribusikan kuesioner didasarkan dari jumlah karyawan di setiap departemen yang dihitung secara proportionate sampling dengan rumus:

$$
n i=\frac{N i}{N} \cdot n
$$

Responden yang diambil dalam penelitian ini adalah karyawan PT. Infineon Technologies Batam yang mana ditetapkan berjumlah 88 orang. Penelitian ini dilakukan dengan menyebarkan kuesioner melalui Hardcopy kepada responden. Dimana pada kuesioner-kuesioner tersebut terdapat karakteristik responden berdasarkan departemen kerja.

Adapun sebagai tambahan tabel 1, dapat dilihat bahwa jumlah responden berdasarkan departemen. Pada departemen Human Resource terdapat sebanyak 10 orang dengan persentase $11 \%$, departemen Quality Management terdapat sebanyak 14 orang dengan persentase $16 \%$, departemen Logistics terdapat sebanyak 32 orang dengan persentase $38 \%$, departemen Information Technology terdapat sebanyak 7 orang dengan persentase 8\%, dan departemen Facilities Management terdapat sebanyak 24 orang dengan persentase $27 \%$.
Tabel 1 Jumlah Sampel per Program Studi

\begin{tabular}{|c|l|c|}
\hline NO & \multicolumn{1}{|c|}{ Departemen } & SAMPEL \\
\hline 1 & $\begin{array}{l}\text { Human Resource } \\
\text { Department }\end{array}$ & 10 \\
\hline 2 & Quality Management & 14 \\
\hline 3 & Logistics & 32 \\
\hline 4 & $\begin{array}{l}\text { Information } \\
\text { Technology }\end{array}$ & 7 \\
\hline 5 & Facilities Management & 24 \\
\hline & Jumlah & 88 \\
\hline
\end{tabular}

Tahapan penelitian ini memakai metode analisis data berikut:

1) Statistik Deskriptif

Statistik deskriptif merupakan metode perhitungan dengan menggunakan median, rata-rata, modus, varians, deviasi standar, dan lainnya yang bertujuan mendeskripsikan gambaran umum dari penyebaran data sampel atau populasi dalam bentuk tabel, diagram, grafik dan lainnya (Kasmadi \& Sunariah, 2014).

2) Statistik Inferensial

Diagram Statistik inferensial merupakan perhitungan statistik dengan tujuan menganalisis data sampel agar dapat dilakukan penarikan kesimpulan terhadap populasi dari sampelnya tentang kesesuaian antara hasil yang diterima dari sampel dengan hasil yang diterima dari populasi (Sugiyono, 2014). Penelitian ini menggunakan statistic inferensial yaitu model uji asumsi klasik, regresi linier berganda, uji $\mathrm{T}$ dan uji F.

\section{Hasil dan Pembahasan}

\subsection{Hasil analisis data}

\subsubsection{Identitas Responden}

Responden yang diambil dalam penelitian ini adalah karyawan PT. Infineon Technologies Batam yang ditetapkan untuk 88 orang. Penelitian ini dilakukan dengan menyebarkan kuesioner melalui Hardcopy kepada responden. 
4.2 Statistik Inferensial dan Uji Asumsi Klasik

Uji Normalitas adalah uji yang direncanakan untuk mensurvei kewajaran peredaran informasi yang ditentukan untuk mengetahui apakah penyampaian informasi tersebar secara teratur. Uji keteraturan informasi yang digunakan dalam pengujian ini adalah Uji Kolmogorov-Smirnov . Seperti yang ditunjukkan oleh Sunariah (2014) pengaturannya adalah bahwa penyebaran informasi disesuaikan secara teratur, untuk lebih spesifik jika nilai Asimtotik Signifikansi (2-diikuti) lebih menonjol daripada nilai alpha 0,05 .

Tabel 2. Uji Normalitas

One-Sample Kolmogorov-Smirnov Test

\begin{tabular}{|ll|r|}
\hline & & \multicolumn{2}{|c|}{$\begin{array}{c}\text { Unstandardized } \\
\text { Residual }\end{array}$} \\
\hline $\mathrm{N}$ & & 88 \\
Normal & Mean & $0 \mathrm{E}-7$ \\
Parameters & Stb \\
& Std. & 4.46943081 \\
Most & Deviation & Absolute \\
Extreme & Positive & .137 \\
Differences & Negative & .099 \\
& Kolmogorov-Smirnov Z & -.137 \\
Asymp. Sig. (2-tailed) & 1.287 \\
\hline
\end{tabular}

a. Test distribution is Normal .

b. Calculated from data .

\subsection{Regresi Linier Berganda}

Analisis regresi linier berganda adalah analisis yang mengukur pengaruh dua atau lebih variabel independen terhadap variabel dependen dan menggunakan variabel tersebut untuk memprediksi variabel dependen. Dalam penelitian ini, analisis regresi linier berganda dilakukan untuk menguji hipotesis. Rumus yang digunakan:

$$
\begin{aligned}
& \mathrm{Y}=\mathrm{a}+\mathrm{b} 1 \times 1+\mathrm{b} 2 \times 2+\mathrm{b} 3 \times 3+\mathrm{e} \\
& \text { Keterangan: } \\
& \mathrm{Y}=\text { Gaya Kepemimpinan } \\
& \mathrm{a}=\text { Konstanta } \\
& \mathrm{b}=\text { Koefisien regresi } \\
& \mathrm{X} 1=\text { Motivasi } \\
& \mathrm{X} 2=\text { Kinerja Karyawan } \\
& \mathrm{e}=\text { term of error }
\end{aligned}
$$

\begin{tabular}{|c|c|c|c|c|c|c|}
\hline \multicolumn{7}{|c|}{ Coefficients $^{\mathrm{a}}$} \\
\hline \multirow{2}{*}{\multicolumn{2}{|c|}{ Model }} & \multicolumn{2}{|c|}{$\begin{array}{l}\text { Unstandardized } \\
\text { Coefficients }\end{array}$} & \multirow{2}{*}{$\begin{array}{c}\begin{array}{c}\text { Standardi } \\
\text { zed } \\
\text { Coefficie } \\
\text { nts }\end{array} \\
\text { Beta }\end{array}$} & \multirow[b]{2}{*}{$\mathrm{t}$} & \multirow[b]{2}{*}{ Sig. } \\
\hline & & B & $\begin{array}{l}\text { Std. } \\
\text { Error }\end{array}$ & & & \\
\hline \multirow[t]{3}{*}{1} & (Constant) & 4.281 & 5.858 & & .731 & .467 \\
\hline & $\begin{array}{l}\text { MOTIVAS } \\
\text { I(X1) }\end{array}$ & 2.105 & .240 & .693 & $\begin{array}{r}8.77 \\
0\end{array}$ & .000 \\
\hline & $\begin{array}{l}\text { KINERJA } \\
\text { KARYAW } \\
\text { AN(X2) }\end{array}$ & .163 & .383 & .034 & .426 & .672 \\
\hline \multicolumn{7}{|c|}{ a. Dependent Variable: GAYA KEPEMIMPINAN(Y1) } \\
\hline
\end{tabular}

4.4 Uji T

Tabel 3. Tabel Uji T

Berdasarkan table 3 dengan mengamati baris, kolom $\mathrm{t}$, dan sig. bisa di jelaskan sebagai berikut:

\section{Pengaruh Gaya Kepemimpinan Terhadap Motivasi (H1)}

Variabel Gaya Kepemimpinan (Y) berpengaruh positif dan besar terhadap inspirasi pekerja di PT. Teknologi Infineon Batam. Hal ini terlihat dari signifikan motivasi (X1) $0,000<0,05$ dan nilai ttabel $=\mathrm{t}(\mathrm{a} / 2 ; \mathrm{n}-\mathrm{k}-1=\mathrm{t}$ $(0,05 / 2 ; 85-2-1)=(0,025 ; 85)=1,98827$

Ini berarti bahwa nilai thitung lebih penting dari pada $t$ tabel $\quad(8,770>1,98827)$ dan kemudian H0 ditolak dan H1 diakui, sehingga secara teori ada kemungkinan pengaruh gaya kepemimpinan terhadap motivasi karyawan.

\section{Pengaruh Gaya Kepemimpinan Terhadap} Kinerja Karyawan (H2)

Variabel Gaya Kepemimpinan (Y) tidak berpengaruh secara positif dan signifikan kinerja karyawan di PT. Infineon Technologies Batam. Hal ini terlihat dari signifikan kinerja karyawan (X2 ) $0.672>0.05$ dan nilai ttabel $=\mathrm{t}(\mathrm{a} / 2 ; \mathrm{n}-\mathrm{k}$ $-1=\mathrm{t}(0.05 / 2 ; 85-2-1)=(0.025 ; 85)=1.98827$. 


\subsection{Uji F}

Tabel 5 Tabel Uji F

\begin{tabular}{|c|c|c|c|c|c|c|}
\hline \multicolumn{7}{|c|}{ ANOVA $^{\mathrm{a}}$} \\
\hline \multicolumn{2}{|c|}{ Model } & $\begin{array}{l}\text { Sum of } \\
\text { Squares }\end{array}$ & df & $\begin{array}{l}\text { Mean } \\
\text { Square }\end{array}$ & $\mathrm{F}$ & Sig. \\
\hline \multirow[t]{3}{*}{1} & Regression & 1675.559 & 2 & 837.779 & 40.976 & $.000^{\mathrm{b}}$ \\
\hline & Residual & 1737.896 & 85 & 20.446 & & \\
\hline & Total & 3413.455 & 87 & & & \\
\hline \multicolumn{7}{|c|}{ a.DependentVariable: GAYA.KEPEMIMPINAN(Y1) } \\
\hline \multicolumn{7}{|c|}{$\begin{array}{l}\text { b.Predictors:(Constant),KINERJA.KARYAWAN(X2), } \\
\text { MOTIVASI(X1) }\end{array}$} \\
\hline
\end{tabular}

Berdasarkan hasil pengujian pada table 4.5 dapat dilihat pada nila $\mathrm{f}$ hitung sebesar 40.976 dengan niali $\mathrm{f}$ tabel adalah 3.10 sehingga nilai $\mathrm{f}$ hitung $>$ ftabel atau $40.976>3.10$, dan tingkat signifikan $0.000<0.05$ maka H0 ditolak dan H1 diterima, artinya variabel bebas motivasi dan kinerja karyawan memiliki pengaruh positif dan signifikan terhadap gaya kepemimpinan.

\section{Kesimpulan}

Berdasarkan hasil penelitian tentang faktor yang dilakukan bertujuan untuk mengetahui analisis pengaruh faktor gaya kepemimpinan dalam mempengaruhi minat motivasi dan kinerja karyawan PT. Infineon Technologies Batam. Maka kesimpulan penelitian ini adalah sebagai berikut:

1) Faktor gaya kepemimpinan dengan variabel motivasi berpengaruh positif dan signifikan dalam meningkatkan motivasi kerja karyawan PT. Infineon Technologies Batam. Dengan ini Hipotesis 1 yang berbunyi "Faktor gaya kepemimpinan mempunyai pengaruh positif terhadap motivasi karyawan di PT. Infineon Technologies Batam.” Dinyatakan dapat diterima dan dapat dibuktikan pada variabel motivasi masing-masing item pernyataan memiliki mean di daerah postif dengan total variabel mean motivasi (X1) sebesar 3.896 juga berada pada daerah positif dengan nilai signifikan $\mathrm{t}$ motivasi (X1) 0.000 lebih kecil dari $0.05(0.000<0.05)$ dan nilai thitung lebih besar dari ttabel $(8.770>1.98827)$ yang berarti $\mathrm{H} 0$ di tolak dan $\mathrm{H} 1$ diterima.
Hal ini sesuai dengan penelitian terdahulu mengacu .pada sejumlah hasil informasi yang disampaikan oleh (Niklas K.Steffens, 2018) menyatakan gaya kepemimpinan berpengaruh positif dan signifikan terhadap motivasi karyawan.

2) Faktor gaya kepemimpinan dengan variabel kinerja karyawan berpengaruh positif dan signifikan dalam meningkatkan kinerja karyawan di PT. Infineon Technologies Batam. Dengan ini Hipotesis 2 yang berbunyi "Faktor gaya kepemimpinan berpengaruh terhadap kinerja karyawan di PT. Infineon Technologies Batam." dinyatakan dapat diterima dan dapat dibuktikan nilai total mean pada variabel kinerja karyawan (X2) bernilai 3.97 dan memang berada di daerah positif. Namun nilai signifikan $\mathrm{t}$ kinerja karyawan (X2) 0.672 lebih besar dari $0.05(0.672>0.05)$ dan nilai thitung lebih kecil dari ttabel $(0.426<$ 1.98827) yang berarti $\mathrm{H} 0$ di terima dan $\mathrm{H} 2$ ditolak. Namun hal ini tidak sesuai dengan peneltian terdahulu oleh (Bella Nelfa Audina, 2019) dan (Trenggono Widodo, 2018) yang menyatakan gaya kepemimpinan berpengaruh positif dan signifikan terhadap kinerja karyawan.

\section{Daftar Pustaka}

A.Audina, Bella Nelfa. "Pengaruh Gaya Kepemimpinan dan Komunikasi terhadap Kinerja Karyawan Pada PT Bintang Rezeki Maju Medan." Aksara Public 3.3 (2019): 3747.

B. Asrar-ul-Haq, Muhammad \& Kuchinke, K.. (2016). Impact of leadership styles on employees' attitude towards their leader and performance: Empirical evidence from Pakistani banks. Future Business Journal. 2.

C. Kasmadi, \& Sunariah. (2014). Panduan Modern Penelitian Kuantitatif. Bandung: Alfabeta.

D. Kesuma, B. (2019). Analisis Kepemimpinan terhadap kinerja karyawan di Perusahaan.

E. Sugiyono. (2014). Metode Penelitian Pendidikan Pendekatan Kuantitatif dan R\&D. Bandung: Alfabeta.

F. Trenggono Widodo, N. A. (2018). Analisis Pengaruh Gaya Kepemimpinan, Disiplin Kerja dan Pelatihan Kerja Terhadap Kerja Karyawan Di PT Telkom Indonesia Cabang Batam. Jurnal Industri Kreatif (JIK), 101.

G. Van D R, Fink L, Steffens NK, Peters K, Haslam SA. Attributions of leaders' charisma increase after their death: The mediating role of identity leadership and identity fusion. Leadership. 2019;15(5):576-589. 